Jurnal Konstruksi Hukum | ISSN: XXXX | E-ISSN: XXXX Vol. 1, No. 2, Oktober 2020, Hal. 404-408| Available Online at https://www.ejournal.warmadewa.ac.id/index.php/jukonhum DOI: https://doi.org/10.22225/jkh.1.2.2538.404-408

\title{
PERLINDUNGAN HUKUM PENYEWA TERHADAP OBJEK HAK TANGGUNGAN YANG DIBEBANI HAK SEWA
}

\author{
I Made Adi Saputra, A.A Sagung Laksmi Dewi, Luh Putu Suryani \\ Fakultas Hukum Universitas Warmadewa, Denpasar - Bali, Indonesia
}

\begin{abstract}
Abstrak
Bank merupakan badan usaha yang mengumpulkan uang dari publik berbentuk deposito dan menyalurkan ke public berbentuk kredit. Prinsip bank menetapkan bahwa agunan di perlukan untuk memberikan kredit kepada pelanggan. Permasalahan hukum di ruang lingkup kewajiban isi dari jurnal ini diilustrasikan oleh suatu objek, disewakan oleh debitur kepada pihak ketiga tidak dengan sepengetahuan kreditor, yang dasar akhir objeknya ialah hipotek dieksekusi. Kajian ini menelaah bagaimana perlindungan hukum bagi penyewa terkait objek hipotek yang dieksekusi dan prosedur pelaksanaan objek hipotek yang disewa. Penelitian ini dilakukan menggunakan desain penelitian hukum normatif dengan pendekatan studi legislasi. Pendekatan legislasi dilakukan dengan memeriksa masalah (masalah hukum) yang sedang dihadapi. Hasil penelitian mengungkap bahwa perlindungan hukum bagi penyewa terkait objek hipotek yang disewa dapat dilihat dari peraturan Pasal $1576 \mathrm{BW}$, yang menetapkan bahwa penyewa dapat mempertahankan haknya dengan alasan bahwa penjual tidak dapat membatalkan sewa, tetapi hanya dapat mempertahankan haknya dan pihak yang menyewakan dengan kompensasi untuk akhir hubungan sewa. Perlindungan hukum untuk menuntut pihak yang menyewakan terkait dengan sewa muncul karena pihak yang menyewakan telah mengabaikan kinerjanya sebagaimana dimaksud dalam Pasal 1550 BW. Prosedur untuk mengeksekusi objek hak tanggungan yang dibebani hak sewa dimulai dengan mengajukan permohonan dan berakhir dengan eksekusi. Permintaan eksekusi dilakukan dengan mengajukan aplikasi yang diajukan langsung ke Ketua Pengadilan Distrik dengan melampirkan fotocopy keputusan pengadilan (Keputusan Pengadilan Negeri dan/atau keputusan Mahkamah Agung) yang memiliki kekutatan hukum permanen. Pihak yang berhak melakukan permohonan eksekusi ialah pihak yang dinyatakan unggul dalam isi putusan pengadilan, baik dilakukan secara pribadi maupun melalui pengacaranya yang disertai dengan surat kuasa khusus.
\end{abstract}

Kata Kunci: Hak Tanggungan; Penyewa; Perlindungan Hukum

\begin{abstract}
As a business entity collecting money from the public and channeling it back to the public, the bank principle stipulates that collateral is required to provide credit to customers. The legal problem related to the bank studied in this study is that the object leased by the debtor to a third party is not with the knowledge of the creditor, whose final object is the executable mortgage. This study examines the legal protection for tenants related to executed mortgage objects and what the procedures for implementing the leased mortgage object are. This research was conducted using a normative legal research design with a legislation study approach. The legislative approach is realized by examining the problems (legal problems) that are being faced. The research results reveal that the legal protection for tenants related to the leased mortgage object can be seen from the regulation of Article $1576 \mathrm{BW}$, which stipulates that tenants can retain their rights on the grounds that the seller is not permitted to cancel the lease, but shall only defend their rights and the lessee with compensation for the end of the lease relationship. Legal protection demands that the lessee in relation to the lease appears because the lessee has neglected its performance as referred to in Article $1550 \mathrm{BW}$. The procedure for executing an object of mortgage bearing lease rights begins with filing an application and ends with execution. Requests for execution are made by submitting an application directly to the Head of the District Court by attaching a photocopy of court decisions (District Court decisions and / or Supreme Court decisions) which have permanent legal force. The party having the right to request execution is the party declared superior in the content of the court decision, either personally or through the lawyer, accompanied by a special power of attorney.
\end{abstract}

Keywords: Mortgage,; Tenant; Legal Protection 


\section{PENDAHULUAN}

Bank ialah badan usaha yang mengumpulkan dana berasal dari publik dan berbentuk kredit biasa jadi bentuk lain untuk meningkatkan kehidupan banyak orang seperti tertera pada Pasal 1 ayat 2 UndangUndang Nomor 10 tahun 1998 tentang perubahan UU No 7 tahun 1992 tentang perbankan (UU Perbankan). Dikatakan bahwa bank bisa mengumpulkan dana yang bersumber di masyarakat berbentuk Simpanan, Giro, tabungan dan bisa berbentuk serupa lainnya sebagaimana tercantum pada Pasal 1 ayat 5 UU Perbankan yang menentukan bahwa bank memiliki fungsi sebagai penyalur kepada masyarakat berbentuk pinjaman ialah salah satu upaya pemerintah untuk seluruh rakyat Indonesia (Jumhana, 2000). Bagian yang dapat dinilai oleh bank yaitu adanya jaminan yang diberikan debitur kepada bank untuk memberikan fasilitas kredit. Memberikan jaminan ini merupakan perjanjian tambahan di perjanjian kredit itu sendiri (Oktafiani \& Idris, 2015; Sukmawati, 2019). Kemungkinan ini merupakan tambahan memiliki peran yang pasti bagi bank untuk memberikan kepercayaan kepada bank dan kepastian debitur untuk membayar kembali pinjaman dengan menjamin propertinya sebagai jaminan pembayaran kembali hutang atau kredit.

Masalah hukum di ruang lingkup hak hipotik dalam makalah, diilustrasikan oleh keadaan dimana objek yang di sewakan oleh debitur terhadap Pihak ketiga tanpa sepengetahuan kreditur memang perbuatan yang menyimpang dari Pasal 11 Ayat 2 UUHT, ialah janji untuk pembatas kewenangan pemberi pinjaman untuk memiliki atau membuat perjanjian tertulis di muka melalui pemegang hipotek (hak tanggungan). Contoh nyata dari masalah hukum yang diuraikan di makalah ini, contoh permasalahan yang penulis adopsi dalam penulisan makalah ini, dan akan dianalisis nanti ialah permasalahan yang telah diputuskan oleh putusan pengadilan dengan kekuatan hukum tetap, yaitu Pengadilan Keputusan No. 9/PDT.G/2013/PN.JKTBAR, seperti berikut: Terdakwa ialah penyewa untuk sepetak tanah dan bangunan di tanah tersebut memiliki luas $120 \mathrm{~m}^{2}$ yang terletak dan secara lokal diketahui sebagai Jalan KH Hasyim Ashari No.7 A RT 002 RW 004 Desa Duri Pulo Kecamatan Banggunan No.1392/ Duri Pulo, Surat Ukur tanggal 19-09-1998 yang diterbitkan dari kantor Pertanahan Jakarta Pusat, tanggal 20-09-1999 bersama dengan banggunan atau Rumah toko yang ada dibangung di atas tanah (lainnya disebut tanah sengketa) disewakan dari terdakwa II/ pemilik tanah. Dalam kasus sengketa, Penggugat telah membayar penuh dan cash kepada terdakwa II, dan tampaknya terdakwa II memiliki kemestian dalam bentuk pinjaman/ kredit untuk bank sebagai jaminan terdakwa II tidak membayar hutang karena bank mengeksekusi objek sewa. Eksekusi dilakukan dengan menjual atau melelang, mereka yang membeli tanah ialah Terdakwa I. Terdakwa tidak dapat mengosongkan objek, dimana hak sewa pada pasal 1576 KUH Perdata (Burgelijk Wetboek) yang diterjemahkan dalam bahasa Indonesia dengan R. Subekti bersama Tjitro Sudibio (sekarang disebut BW), yang menyatakan bahwa pembelian A dan penjualan tidak memutuskan hak sewa. Oleh karena itu, Pembeli termasuk Terdakwa I karena Terdakwa I dan II melakukan itikad buruk dan mengambil tindakan yang melanggar hukum.

Berdasarkan uraian di atas, penelitian ini bertujuan untuk menganalisis dan mengevaluasi prosedur pelaksanaan hipotek yang dibebani dengan hak hipotik dan memberikan perlindungan hukum untuk penyewa terhadap objek hak sewa yang dibebani dengan hipotek.

\section{METODE PENELITIAN}

Penelitian ini menggunakan jenis penelitian hukum normatif dengan studi perundang-undangan. Penelitian ini dilakukan dengan mencari semua bahan hukum dan peraturan yang berkaitan dengan permasalahan yang ditelitii, misalnya dengan mempelajari secara konsisten, kesesuaian antara Hukum Dasar dengan hukum, antara satu hukum dan peraturan hukum/ pengadilan. Sumber bahan hukum yang dipakai jurnal ini bersumber dari bahan hukum primer dan sekunder. Bahan hukum primer yang dipakai untuk penelitian ini ialah: UU RI Nomor 5 Tahun 1960 Tentang Peraturan Dasar Agraria, UU RI Nomor 4 Tahun 1996 Tentang Hak Tanggungan; UU RI Nomor 101998 Tentang Perubahan Atas UU No 7 Tahun 1992 Tentang Perbankan; Putusan Pengadilan No. 09/PDT.G/2013/PN.JKTBAR. Sedangkan, bahan hukum sekunder digunakan berdasarkan literatur, buku-buku, terkaitan dalam penelitian yang membahas hasil makalah, mahakarya di kalangan hukum. Teknik mengumpulkan bahan hukum menggunakan penelitian normatif dimulai dengan inventarisasi undang-undang, kutipan, rangkuman, dan memberikan ulasan terkait untuk masalah yang di bahas. Setelah bahanbahan hukum di peroleh untuk dikumpulkan, bahan-bahan hukum kemudian diolah dan di analisis dengan argumentasi hukum berdasarkan logika hukum deduktif - induktif (umus-khusus) dituangkan 
secara deskriptif dalam bentuk jurnal yang nantinya akan menghasilkan kesimpulan yang logis terhadap permasalahan yang di bahas.

\section{HASIL DAN PEMBAHASAN}

Perlindungan Hukum Penyewa terhadap Objek Hak Tanggungan yang Dibebani Hak Sewa

Dalam menyewa ada beberapa elemen penting yaitu Subjek, objek, akta, dan masa sewa (Zakki, 2013). Subjek dari sewa, ialah bahwa kedua belah Pihak terikat atau terikat sendiri dalam kegiatan leasing. Mereka ialah penyewa dan penyewa. Objek sewa ialah objek dan harga sewa. Objek ini dalam arti kepemilikan asli orang atau lembaga yang menyewakan, yang memiliki status hukum dalam hukum (Aprilianti, 2011). Tindakan sewa menyewa diwujudkan jika telah ada perjanjian antara kedua Pihak antara penyewa dan yang menyewa, termasuk persetujuan, penyerahan, pembayaran sewa, waktu sewa, ketentuan sewa dan periode sewa. Dari Pasal 1320 KUHPerdata, perjanjian itu sah jika memenuhi 4 syarat, yang pertama ialah perjanjian, kemampuan untuk membuat perjanjian, Ada hal tertentu, ada hal cause halal. Jika keadaan awal dan selanjutnya tidak tercapai, maka perjanjian pasti dapat dipastikan batal. Definisinya ialah satu Pihak dapat melaporkan ke pengadilan dengan tujuan agar membatalkan perjanjian yang disepakati. Akan tetapi ketika salah satu terdakwa dalam perjanjian tidak mempermasalahkan, perjanjian tersebut masih sah. Persyaratan yang ketiga dan keempat tidak tercapai, perjanjian itu batal demi hukum. Ini berarti sejak awal perjanjian dianggap tidak ada. Perlindungan hukum untuk pemegang hak hipotek yang objeknya disewa tergantung dalam perjanjian yang tercantum oleh isi akta pemberian hak (APHT) dimana isi dari pasal 11 ayat 2 UU Tentang Hipotek. Perjanjian dalam akta pemberian hak yang membatasi debitur untuk menyewa objek hipotek, jika dilanggar, pemegang hak kepemilikan sebagai pemegang hak atas objek hak lebih istimewa dibandingkan dengan penyewa yang memiliki hak pribadi untuk Pihak leasing (Poesoko, 2007).

Berdasarkan uraian kepemilikan dan hak sewa diatas, pada dasarnya pemilik rumah memiliki hak untuk menjaminkan rumah kepada bagian bank. Namun, tindakan pemilik rumah untuk menjaminkan rumah, mungkin tidak menyebabkan kerugian bagi penyewa. Hak penyewa untuk menuntut pemilik rumah yang berhubungan dengan sewa muncul jika pemilik rumah mengabaikan kinerjanya yang tercantum dalam Pasal 1550 KUHP, salah satunya ialah bahwa ia tidak dapat memberikan damai bagi Pihak penyewa kepada Pihak yang rumahnya disewakan. Ini karena jika rumah yang dijaminkan akhirnya dieksekusi karena default pemilik rumah kepada bagian bank maka kemungkinan orang tersebut akan terganggu. Untuk gangguang ini, penyewa dapat menuntut berdasarkan default. Jika salah satu Pihak dalam perjanjian menyimpang (default) maka ia bisa mendapatkan perlindungan berdasarkan Pasal 1243 KUHPerdata tentang perubahan dalam biaya, kerugian, dan bunga karena tidak memenuhi perjanjian.

Satrio menjelaskan consensus untuk kehendak-kehendak dimana ia akan bertemu satu sama lain dan kehendak harus dilakukan (Satrio, 1993). Definisi kehendak harus berupa pernyataan bahwa ia ingin menjalani hubungan hokum. Dalam menyelesaikan perselisihan, bisa melalui pengadilan atau diluar pengadilan (Subekti, 2004). Sengketa resolusi diluar pengadilan untuk mencapai kesepakatan tentang bentuk dan jumlah kompensasi atau untuk melakukan hal-hal tertentu untuk memastikan ini tidak akan terjadi lagi. Sedangkan penyelesaian sengketa melalui pengadilan ditunjukan melalui keputusan pengadilan. Sehubungan dengan masalah hukum yang sedang dibahas, untuk menyelesaikan masalah ini, analisis mendalam dari sengketa hukum dalam perjanjian akan dilakukan, Putusan Pengadilan Nomor 09/PDT.G/2013/PN.JKTBAR. Selanjutnya atas dasar wanprestasi tersebut, terdakwa I selaku pemegang hak tanggungan atas jaminan SHGB No.1392/ Duri Pulo (Obyek Hak Tanggungan) telah mengajukan permohonan lelang kepada terdakwa II. Bahwa lelang atas Obyek Hak Tanggungan SHGB No.1392/ Duri Pulo telah dilakukan sebanyak 3 kali, dimana dalam pelelangan pertama dan kedua tidak terjual dengan terdakwa I ditunjuk sebagai pemenang lelang yang sah. Berdasarkan Uraian-uraian tersebut, terbukti bahwa proses dimulainya Perjanjian Kredit, Pemberian SHGB No.1392/Duri Pulo sebagai jaminan, pemberian SKMHT dan pembebanan Hak Tanggungan, hingga pelaksanaan lelang telah sah secara hukum. Oleh karena itu Terdakwa I menolak penyebutan SHGB No.1392/ Duri Pulo sebagai Tanah Sengketa karena sama sekali tidak berdasarkan hukum dan tidak terbukti kebenarannya menurut Pasal 1131 Undang-Undang Hukum Perdata. 


\section{Perlindungan Hukum untuk Penyewa terhadap Objek Hak Sewa yang Dibebani dengan Hipotek}

Kemudahan dalam melakukan eksekusi hak hipotek dan memberikannya kepada pemegang hak khusus kreditor dalam bentuk droit de preferensi dan driot suite adalah karakteristik hak hipotek sebagai lembaga keamanan tanah yang kuat dan khas. Sehubungan dengan itu, semua prosedur dalam menetapkan hak hipotek ini diatur secara terperinci perlu di perhitungkan, sehingga hak istimewa yang diberikan dapat dinikmati oleh kreditor yang bersangkutan. Berdasarkan pertimbanganpertimbangan majelis hakim berpendapat bahwa Penggugat mampu membuktikan Terdakwa II melakukan perbuatan melawan hukum, akan tetapi tidak membuktikan bahwa Terdakwa I telah melakukan perlawanan hukum. Pengugat mendalilkan dan akibat perbuatan melawan hukum yang dilakukan Terdakwa I dan Terdakwa II telah menimbulkan kerugian kepada Penggugat. Terdakwa I tidak terbukti telah melakukan perlawanan hukum, dan hanya Terdakwa I yang terbukti telah berani perbuatan melawan hukum, dan karena itu hanya Terdakwa II harus menanggung kerugian Penggugat tersebut. Sejak Desmber 2012 Terdakwa tidak dapat menikmati barang sewaan, yang berarti bahwa jika dihitung dengan periode sewa yang harus dimiliki Pelapor atas objek sengketa untuk 7 lainnya (tujuh tahun). Periode sewa adalah 7 (Tujuh Tahun), jika dinilai dari harga sewa selama 10 tahun iyalah IDR.2.000.000.000 (dua miliar rupiah) maka nilainya 7/10 x IDR. 2.000.000.000 = 1.400.000.000 (satu miliar empat ratus juta rupiah). Pelapor juga berpendapat bahwa pelapor mengalami kerusakan pada property pelapor yang di keluarkan dari objek sengketa, tetapi tidak ada bukti tunggal yang menunjukan barang-barang di toko objek sengketa ketika objek di kosongkan oleh orang yang tidak di kenal. Oleh karena itu, bukti tidak dapat digunakan sebagai patokan untuk menentukan kerugian pelapor atas kerusakan barang yang dilepas dari objek toko sengketa.

Penggugat juga percaya bahwa sebagai akibat dari dari tidak dapat menikmati hak sewa atas tanah dan rumah toko dari objek yang di sengketakan, ia telah kehilangan keuntungan sejumlah IDR. 50.000.000 (lima puluh juta rupiah), setiap bulan, dimana tidak jelas, permintaan tidak dapat ditrima. Penggugat dalam gugatannya juga meminta agar terdakwa I dan terdakwa II dihukum membayar $1 \%$ dari bunga saat ini setiap bulan. Mengenai hal ini, majelis hakim berpendapat bahwa hanya terdakwa II yang terbukti melakukan tindakan menentang hukum dan karena hukuman hanya akan dikenakan pada terdakwa II, sedangkan permintaan untuk membayar bunga saat ini terbukti, menurut MH jika terdakwa II dibebani dengan bunga sehinggga terdakwa II serius dan tidak membayar kerugian pelapor dibiarkan terus.

\section{SIMPULAN DAN SARAN \\ Simpulan}

Berdasarkan uraian yang dijelaskan sebelumnya, kesimpulan dapat ditarik sebagai berikut:

1. Perlindungan hukum penyewa terhadap objek hak hipotik yang disewakan bisa dilihat berdasarkan peraturan Pasal 1576 BW, Ialah penyewa dapat mempertahankan hak serta alasan bahwa penjualan tidak dapat menghapus sewa, tetapi hanya dapat mempertahankan haknya kepada mereka yang menyewa serta menuntut kompensasi untuk pemutusan hubungan sewa. Perlindungan hukum penyewa untuk menggugat Pihak yang menyewa terkait serta, sewa muncul karena bagian leasing telah mengabaikan kinerjanya (default) sebagaimana dimaksud isi Pasal $1550 \mathrm{BW}$.

2. Eksekusi objek hak hipotik yang dibebani hak sewa dimulai dari mengajukan aplikasi untuk eksekusi sehingga berakhir dengan eksekusi. Permintaan eksekusi dilakukan dari mengajukan aplikasi di ajukan langsung ke Ketua Pengadilan Negri juga melampirkan foto copy keputusan pengadilan (keputusan Pengadilan Negri, dan/atau keputusan Mahkamah Agung) yang memiliki hukum tetap memaksa. Terdakwa memiliki hak untuk menyajikan permohonan eksekusi ialah pihak yang dinyatakan unggul berdasarkan keputusan dari pengadilan, pribadi atau melalui pengacaranya disertai dengan surat kuasa khusus.

\section{Saran}

Berlandaskan penjelasan sebelumnya, beberapa saran dapat diajukan sebagai berikut:

1. Konseling hukum harus dilakukan secara terintegrasi oleh Badan Pertanahan Nasional secara independen bekerjasama dengan pihak-pihak yang terkait dengan kepentingan, sehingga masyarakat dapat memahami pentingnya memiliki Sertifikat Kepemilikan Tanah yang menjadi objek Hak Tanggungan. 
2. Sistem pendaftaran tanah di Indonesia harus didistribusikan secara merata didaerah perkotaan dan perdesaan, terutama desa-desa yang tingkat ekonomi lemah, dan di daerah pedesaan yang tidak mengerti bagaimana tanah didaftarkan dan pentingnya sertifikat tanah.

\section{DAFTAR PUSTAKA}

Aprilianti. (2011). Perjanjian Sewa Guna Usaha antara Lessee dan Lessor. Fiat Justisia Jurnal Ilmu Hukum, 5(3), 315-323.

Jumhana, M. (2000). Hukum Perbankan di Indonesia. Bandung: Citra Aditya Bakti.

Oktafiani, L., \& Idris, I. (2015). Pelaksanaan Pemberian Kredit dengan Jaminan Hak Tanggungan pada Debitur PT. Bank DKI Jakarta Pusat. Lex Jurnalica, 12(2), 79-90.

Poesoko, H. (2007). Parate Execute Obyek Hak Tanggungan (Inkonsisten, Konflik Norma, dan kesehatan Penalaran dalam UUHT). Yoygakarta: LaksBang Preesindo.

Satrio, J. (1993). Hukum Jaminan: Hak-Hak Jaminan Kebendaan. Bandung: Citra Aditya Bakti.

Subekti, R. (2004). Bunga Rampai Ilmu Hukum (Cet. IV). Bandung: Alumni.

Sukmawati, M. N. (2019). Personal Guarante Terhadap Perjanjian Kredit Dengan Jaminan Hak Tanggungan. Airlangga Development Journal, 3(1), 54.

Zakki, M. I. (2013). Transaksi Leasing di Indonesia dalam Perspektif Hukum Islam. Epistemé: Jurnal Pengembangan Ilmu Keislaman, 8(1). 